\title{
Outbreak
}

\section{Early detection and control of an Acinetobacter baumannii multi-resistant outbreak in a hospital in Quito, Ecuador}

\author{
Mónica Cartelle Gestal ${ }^{1}$, Jeannete Zurita ${ }^{1,2}$, Gabriela Gualpa $^{3}$, Cecibel González $^{1}$, Ariane Paz y Miño ${ }^{1}$ \\ ${ }^{1}$ Biomedical Research Unit, Zurita and Zurita Laboratories, Avenida de la Prensa, Quito, Ecuador \\ ${ }^{2}$ Facultad de Medicina., Pontificia Universidad Católica del Ecuador, Quito, Ecuador \\ ${ }^{3}$ Servicio de Laboratorio Clínico Northospital, Comité de Vigilancia y Control de Infecciones, Northospital, Quito, \\ Ecuador
}

\begin{abstract}
Introduction: Acinetobacter baumannii (ABA) is an important opportunistic pathogen associated with high mortality rates in intensive care units (ICUs). An outbreak in the ICU of a secondary-level hospital in Quito, Ecuador, occurred during April and May 2015 and was successfully controlled.

Methodology: Enterobacterial repetitive intergenic consensus polymerase chain reaction (ERIC-PCR) and repetitive element palindromic (REP)-PCR was conducted on all isolates recovered from patients, as well as environmental samples, to confirm the presence of an outbreak. A case-control study was conducted by comparing the clinical histories of the affected patients and of control patients present in the ICU during the outbreak period who did not present a positive culture for ABA.

Results: Five patients were infected and two were colonized with the same clonal strain of ABA, which was also identified on the stethoscope and a monitor associated with an isolation room. Statistical analysis of case histories did not identify any additional risk factors, but the outbreak was initiated by one patient in the isolation room of the ICU who was infected with the outbreak strain. All patients who ocupied that room after the index case tested positive for at least one culture of ABA. The outbreak strain was found on the stethoscope, and a subclone was found on the monitor of that room.

Conclusion: Having access to basic equipment will enable well-trained professionals to rapidly detect and initiate the control process of an outbreak, saving lives and money spent on nosocomial infection treatments.
\end{abstract}

Key words: outbreak; Acinetobacter baumannii; nosocomial infections; control; ABA.

J Infect Dev Ctries 2016; 10(12):1294-1298. doi:10.3855/jidc.7544

(Received 13 August 2015 - Accepted 02 November 2015)

Copyright (C) 2016 Gestal et al. This is an open-access article distributed under the Creative Commons Attribution License, which permits unrestricted use, distribution, and reproduction in any medium, provided the original work is properly cited.

\section{Introduction}

Acinetobacter baumannii (ABA) is a ubiquitous microorganism able to colonize and survive in diverse environments; for these reasons, $\mathrm{ABA}$ is difficult to control in hospitals, and outbreaks have been reported around the world [1-6]. Because ABA is a major opportunistic pathogen pervasive in the environment, it constitutes a leading cause of cross-contamination and infections, particularly multidrug-resistant (MDR) infections associated with high mortality rates in intensive care units (ICUs) $[3,6,7]$. In Latin America, few outbreak studies of ABA have been published, the first being in Brazil in 2003 [4]. The situation of MDR $\mathrm{ABA}$ is of particular concern in developing countries, such as Ecuador, where the conditions and policies of hospitals are not always up to date, leading to increases in the risk of nosocomial infections [8].
The aim of this study was to characterize an outbreak of ABA in a hospital in Quito, Ecuador, and to localize the environmental reservoirs and possible risk factors associated with the infections.

\section{Methodology}

Study setting and selection criteria

Between 8 April and 26 May 2015, five patients admitted to the secondary-level, 58-bed hospital were infected; two were colonized by an epidemic MDR strain of ABA (ABA-MDR). The seven patients that presented a positive culture were designated as cases, while five controls were chosen at random from patients admitted to the same unit during the outbreak period.

\section{Measurements}

Infection or colonization with ABA-MDR was documented by the infectious diseases unit. The 
variables studied to determine the risk factors for infection/colonization by ABA-MDR and for the descriptive study of the clinical characteristics of the infected and/or colonized patients were age, previous antibiotic therapy, previous invasive techniques, and any previous hospitalization.

To control the outbreak, infected/colonized patients were isolated and measures were taken to prevent transmission. These measures comprised single use of disposable gloves to examine infected/colonized patients, and cleaning and disinfection of surfaces followed by a deep clean of the isolation room. The room and ICU were then closed for 48 hours as a control measure.
Microbiological analysis

All isolates of the outbreak strain were obtained from clinical specimens. Identification and susceptibility profiles were performed using the VITEK2 compact system (bioMérieux, Durham, USA), following the manufacturer's instructions. Identification was performed using GN (21 341) and the susceptibility profile was determined by microdilution using the AST-GN66 (413 398), both using VITEK2 compact. The criteria proposed by the Clinical and Laboratory Standards Institute (CLSI) [9] were applied in interpreting the sensitivity results. Molecular typing of the isolates (one per patient) was performed by ERIC-PCR and REP-PCR [10-12], and resolving by electrophoresis on agarose $0.8 \% \mathrm{w} / \mathrm{v}$ gels.

Table 1. Case and control patients included in the study. This table shows the clinical features of the cases and control patients included in the study.

\begin{tabular}{|c|c|c|c|c|c|c|c|c|c|c|c|c|c|}
\hline Code & Age & $\begin{array}{c}\text { Days } \\
\text { previous } \\
\text { sample } \\
\text { in } \\
\text { hospital }\end{array}$ & $\begin{array}{c}\text { Isolation } \\
\text { A. } \\
\text { baumannii }\end{array}$ & Sample & $\begin{array}{l}\text { Previous } \\
\text { surgery }\end{array}$ & $\begin{array}{l}\text { Previous } \\
\text { treatment }\end{array}$ & Colonization & Infection & $\begin{array}{c}\text { Other } \\
\text { infection }\end{array}$ & $\begin{array}{l}\text { Invasive } \\
\text { techniques }\end{array}$ & $\begin{array}{l}\text { Central } \\
\text { catheter }\end{array}$ & $\begin{array}{l}\text { Antibiotic } \\
\text { treatment }\end{array}$ & Outcome \\
\hline 2 & 89 & 3 & $26 / 04 / 2015$ & Blood & No & $\begin{array}{l}\text { Levofloxacin } \\
\text { Meropenem } \\
\text { Ciprofloxacin }\end{array}$ & No & Yes & No & No & No & & Alive \\
\hline 3 & 54 & 3 & $27 / 04 / 2015$ & Bedsore & Yes & $\begin{array}{l}\text { Cefazolin } \\
\text { Meropenem } \\
\text { Fluconazole } \\
\text { Amikacin } \\
\text { Levofloxacin } \\
\text { Fosfomycin } \\
\text { Nitrofurantoin } \\
\text { Gentamicin } \\
\text { Linezolid }\end{array}$ & Yes & No & No & Yes & Yes & & Alive \\
\hline 5 & 77 & 3 & $14 / 05 / 2015$ & $\begin{array}{l}\text { Biliary } \\
\text { secretion }\end{array}$ & Yes & $\begin{array}{l}\text { Meropenem } \\
\text { Ciprofloxacin } \\
\text { Ertapenem }\end{array}$ & Yes & No & No & Yes & Yes & & Alive \\
\hline 6 & 39 & 3 & $15 / 05 / 2015$ & $\begin{array}{l}\text { Splenic } \\
\text { bed } \\
\text { lavage }\end{array}$ & Yes & $\begin{array}{l}\text { Piperacillin- } \\
\text { tazobactam } \\
\text { Colistin } \\
\text { Fluconazole } \\
\text { Meropenem } \\
\text { Vancomycin }\end{array}$ & No & Yes & No & Yes & Yes & $\begin{array}{l}\text { Meropenem } \\
\text { Colistin } \\
\text { Vancomycin } \\
\text { Fluconazole }\end{array}$ & Alive \\
\hline 7 & 82 & 3 & $26 / 05 / 2015$ & Blood & No & Ertapenem & No & Yes & No & Yes & Yes & Ertapenem & Death \\
\hline 8 & 83 & 3 & \multicolumn{2}{|c|}{ Control } & Yes & Cefazolin & No & No & Yes & Yes & No & & Alive \\
\hline 9 & 78 & 3 & \multicolumn{2}{|c|}{ Control } & No & $\begin{array}{l}\text { Piperacillin- } \\
\text { tazobactam }\end{array}$ & No & No & Yes & No & No & $\begin{array}{l}\text { Piperacillin- } \\
\text { tazobactam }\end{array}$ & Alive \\
\hline
\end{tabular}




\section{Statistical analysis}

Statistical tests were performed using StatPac software and the t-test (two-sample t-test between percentages).

\section{Results}

\section{Clinical study}

Case histories showed that all the patients involved in the study had been transferred from another hospital and all of them had received previous antibiotic therapy. ABA infections were identified in five, and colonization in the remaining two cases. The average age of patient was $65 \pm 24$, and no statistically significant difference was found between genders (Table 1).

The common factor in all infected or colonized patients was that all had been in the isolation room of the ICU where the outbreak strain was isolated from the room's stethoscope. Results indicated this was the cause of the cross-contamination between patients.

\section{Microbiological study}

Forty-two environmental samples were collected, and the results showed that one ABA strain with the same phenotype was found on a monitor, stethoscope, and mattress (nine other Gram-negative bacteria were also isolated from the environment of the ICU). Twelve samples collected after the cleaning of ICU were all negative.

All isolates of ABA, clinical and environmental, presented the same susceptibility profile (Table 2), all being resistant to all antibiotics except colistin and tigecycline.

Table 2. Minimum inhibitory concentration (MIC) and interpretation of the susceptibility pattern (according to Clinical and Laboratory Standards Institute 2015)

\begin{tabular}{lcc}
\hline Antibiotic & MIC $(\boldsymbol{\mu g} / \mathbf{m L})$ & Interpretation \\
\hline Colistin & $<2$ & Sensitive \\
Levofloxacin & 4 & Intermedium \\
Ceftazidime & 16 & Resistant \\
Imipenem & $>16$ & Resistant \\
Meropenem & $>16$ & Resistant \\
Ciprofloxacin & $>4$ & Resistant \\
Cefepime & $>64$ & Resistant \\
Gentamycin & $>16$ & Resistant \\
Amikacin & $>16$ & Resistant \\
Ampicillin/sulbactam & $>32$ & Resistant \\
Tigecycline* & $22 \mathrm{~mm}$ &
\end{tabular}

*Tigecycline sensibility profile was tested following the Kirby-Bauer method (CLSI 2015).

\section{Genotype studies}

The strains of the seven patients show exactly the same profile. The ABA isolated from the mattress presented a different genotype with both molecular techniques (Figure 1 and 2). When studying the strains with ERIC-PCR, the outbreak clone appeared to be on the stethoscope and monitor (Figure 1). However, when analyzing by REP-PCR, it was evident that the monitor strain was a subclone (Figure 2), confirming REP-PCR as the gold standard for $\mathrm{ABA}$, as the discrimination power is higher than that of ERIC-PCR.

Figure 1. ERIC-PCR of the infected patients with ABA-MDR and three environmental samples of ABA.

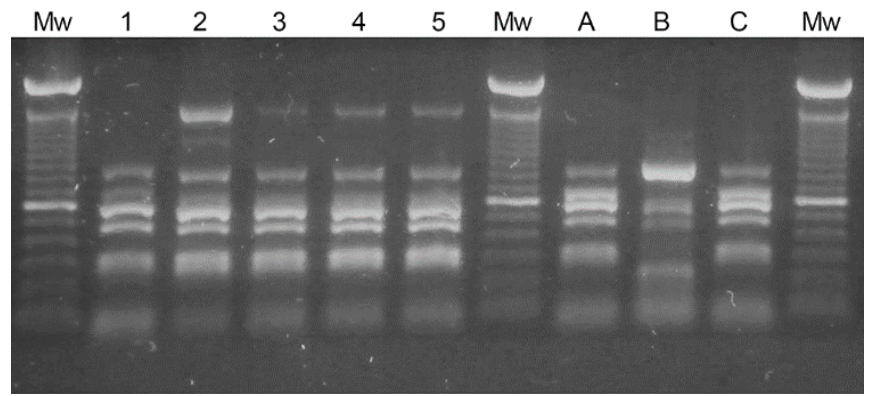

MW: molecular weight marker; lanes 1 to 5 : one isolate of each of the five patients infected with ABA-MDR which show the same profile; Lane A: stethoscope of the isolation room; Lane B: mattress; Lane C: monitor of the isolation room. Lanes $\mathrm{A}, \mathrm{B}$ and $\mathrm{C}$ have the same genetic profile as the outbreak strain, while the lane B (mattress) is a different genotype.

Figure 2. REP-PCR of all the clinical samples and the three environmental strains of $\mathrm{ABA}$

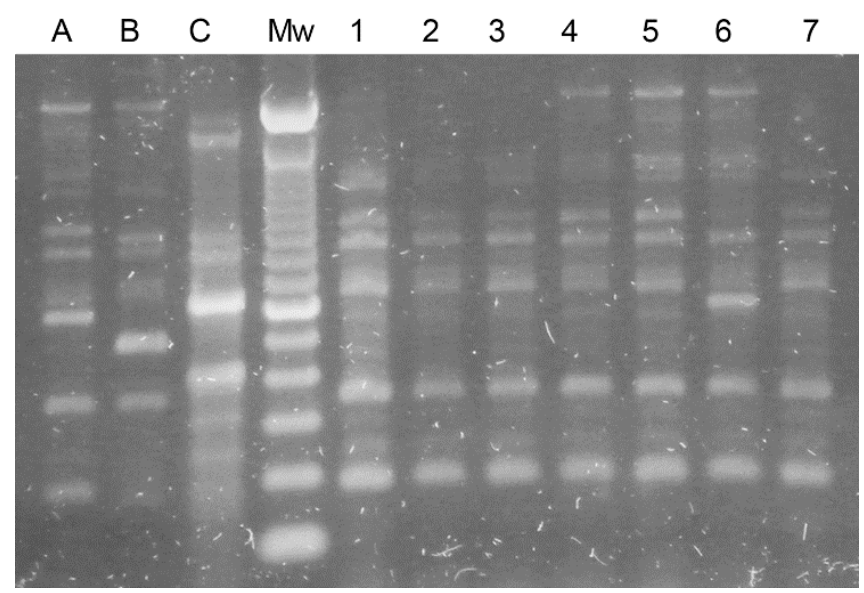

Lane A: stethoscope of the isolation room; Lane B: mattress; lane C: monitor of the isolation room. Lane A (stethoscope of the isolation room) is the outbreak strain, the lane B (mattress) is a different genotype and the lane $\mathrm{C}$ (monitor of the isolation room) is a subclone of the outbreak strain. Lanes 1 to 5: clinical isolates of ABA-MDR infected patients; lanes 6 and 7 clinical isolates of ABA-MDR colonized patients). 
The figure is overlapping the heading and it looks like it is over another photo

Case-controls study

Staying in the isolation room of the ICU was the only risk factor identified. The first patient (run over by a car and transferred from another hospital) was the index case. After he left the isolation room, all other patients who subsequently went into that room developed at least one positive culture for ABA. The strain was isolated from the stethoscope that was exclusively used for the one bed in this room, which was thus considered to be the source of the crosscontamination. However, a subclone strain was identified on the monitor used for the patients in that room.

While the other patients in ICU who did not stay in this isolation room presented other infections, they were not infections caused by the outbreak strain.

No other specific risk factors were found.

\section{Control measurements}

After isolation of the patients, disinfection, and deep cleaning was undertaken, no clinical isolates of ABA were found in the control environmental samples.

\section{Discussion}

Outbreaks caused by ABA-MDR have been described worldwide [1-7,13] yet few studies in the literature refer to Latin America [8]. The few manuscripts investigating adult ICU Gram-negative outbreaks in Latin America and the Caribbean mostly originate from the more affluent nations. No such publications from Ecuador have been found, leaving the scientific community blind to the mortality and morbidity rates associated with these nosocomial outbreaks and the effectiveness of ensuing outbreak management in the distinctive contexts of this Latin American country $[4,8]$.

The lack of dedicated budgets and access to resources makes research difficult to conduct in countries such as Ecuador, but we show that with minimal equipment and costs (USD $\$ 30$ for microbiological diagnosis and USD $\$ 15$ for the molecular characterization of the outbreak, per sample), we were able to detected and stop the dissemination of the outbreak at an early stage, thus dramatically decreasing the costs associated with nosocomial infections, previously costing an average of USD $\$ 2,242$ per day/patient for bed, antibiotics, tests, and imaging. The reported outbreak affected a low number of patients; just seven people presented a positive culture, all with extensive previous antibiotic therapy treatments and more than 72 hours spent in the hospital. These factors have been previously associated with an increased risk of acquiring nosocomial infections $[1,3,4,6,7]$. The outbreak strain was found on the stethoscope of the isolation room in the ICU; this room is considered to be the common factor to all patients infected or colonized by ABA. This room, and more precisely the stethoscope used specifically in the room, was found to be the risk factor for the infection or colonization by the outbreak strain. The crosstransmission was reported previously for ABA, highlighting the importance of hand hygiene and deep cleaning [14]. Once the room was disinfected and closed for 48 hours after cleaning, no more isolates were found, showing the importance of good disinfection and cleaning protocols between patients. A total of two patients died from the outbreak strain; however, no statistical significance was found between infection with the strain and mortality rate $(\mathrm{t}$-statistic $=$ 0.456 and $p=0.672$ with 4 degrees of freedom).

During this study, the rapid detection and decisive actions of the laboratory staff enabled the identification not just of the outbreak itself but also the localization of the sources of transmission, preventing further loss of life and the associated high costs of a prolonged outbreak.

However, the need for antibiotic stewardship is emphasized, as the excessive usage of antibiotics, displayed in the patients' histories, indicates a trend of misuse responsible for high levels of resistance found in Ecuador [15].

\section{Conclusions}

The particular conditions found in hospitals of developing countries such as Ecuador, with severe budget and resource constraints, present unique challenges for the effective care of patients. However, the importance of the strict enforcement of hygiene protocols is emphasized, as the outbreak strain was found on the stethoscope of the isolation room. If the protocol for stethoscope usage between patients had been followed, the outbreak could possibly have been prevented.

Without the rapid detection and action of laboratory and hospital staff, the outbreak could have resulted in many more deaths at great cost. This highlights the importance of well-trained professionals who adhere to good professional practice and effective protocols. It demonstrates that even with limited resources and budgets, detection of outbreaks and control of nosocomial infections can be achieved effectively. 


\section{Acknowledgements}

This project was supported by Zurita \& Zurita Laboratories. Language review was done by Jonathan Gurr. The authors want to acknowledge the help offer by the Northospital to perform and authorization to review medical records was obtained from the Director of the Hospital, Dr. Juan Pablo Aguayo. Dr. Juan Pablo Aguayo and Dr. Fernando Erazo to made possible the access to the information and publication of this manuscript.

\section{References}

1. Del Mar Tomas M, Cartelle M, Pertega S, Beceiro A, Llinares P, Canle D, Molina F, Villanueva R, Cisneros JM, Bou G (2005) Hospital outbreak caused by a carbapenem-resistant strain of Acinetobacter baumannii: patient prognosis and riskfactors for colonisation and infection. Clin Microbiol Infect 11: 540-546.

2. Dettori M, Piana A, Deriu MG, Lo Curto P, Cossu A, Musumeci R, Cocuzza C, Astone V, Contu MA, Sotgiu G (2014) Outbreak of multidrug-resistant Acinetobacter baumannii in an intensive care unit. New Microbiol 37: 185191.

3. Ye D, Shan J, Huang Y, Li J, Li C, Liu X, He W, Li Y, Mao P (2015) A gloves-associated outbreak of imipenem-resistant Acinetobacter baumannii in an intensive care unit in Guangdong, China. BMC Infect Dis 15: 179.

4. Dalla-Costa LM, Coelho JM, Souza HA, Castro ME, Stier CJ, Bragagnolo KL, Rea-Neto A, Penteado-Filho SR, Livermore DM, Woodford N (2003) Outbreak of carbapenem-resistant Acinetobacter baumannii producing the OXA-23 enzyme in Curitiba, Brazil. J Clin Microbiol 41: 3403-3406.

5. Teo J, Lim TP, Hsu LY, Tan TY, Sasikala S, Hon PY, Kwa AL, Apisarnthanarak A (2015) Extensively drug-resistant Acinetobacter baumannii in a Thai hospital: a molecular epidemiologic analysis and identification of bactericidal Polymyxin B-based combinations. Antimicrob Resist Infect Control 4: 2.

6. Markogiannakis A, Fildisis G, Tsiplakou S, Ikonomidis A, Koutsoukou A, Pournaras S, Manolis EN, Baltopoulos G, Tsakris A (2008) Cross-transmission of multidrug-resistant Acinetobacter baumannii clonal strains causing episodes of sepsis in a trauma intensive care unit. Infect Control Hosp Epidemiol 29: 410-417.

7. Senok A, Garaween G, Raji A, Khubnani H, Kim Sing G, Shibl A (2015) Genetic relatedness of clinical and environmental
Acinetobacter baumanii isolates from an intensive care unit outbreak. J Infect Dev Ctries 9: 665-669.

8. Luna CM, Rodriguez-Noriega E, Bavestrello L, GuzmánBlanco M (2014) Gram-negative infections in adult intensive care units of latin america and the Caribbean. Crit Care Res Pract 2014: 480463.

9. Clinical and Laboratory Standards Institute (2015) Performance standards for antimicrobial susceptibility testing; twenty-fifth information supplement. M100-S25.

10. Cartelle M, del Mar Tomas M, Pertega S, Beceiro A, Dominguez MA, Velasco D, Molina F, Villanueva R, Bou G (2004) Risk factors for colonization and infection in a hospital outbreak caused by a strain of Klebsiella pneumoniae with reduced susceptibility to expanded-spectrum cephalosporins. J Clin Microbiol 42: 4242-4249.

11. Vila J, Marcos MA, Jimenez de Anta MT (1996) A comparative study of different PCR-based DNA fingerprinting techniques for typing of the Acinetobacter calcoaceticus-A. baumannii complex. J Med Microbiol 44: 482-489.

12. Higgins PG, Hujer AM, Hujer KM, Bonomo RA, Seifert H (2012) Interlaboratory reproducibility of DiversiLab rep-PCR typing and clustering of Acinetobacter baumannii isolates. J Med Microbiol 61: 137-141.

13. Waterman PE, McGann P, Snesrud E, Clifford RJ, Kwak YI, Munoz-Urbizo IP, Tabora-Castellanos J, Milillo M, Preston L, Aviles R, Sutter DE, Lesho EP (2013) Bacterial peritonitis due to Acinetobacter baumannii sequence type 25 with plasmidborne new delhi metallo- $\beta$-lactamase in Honduras. Antimicrob Agents Chemother 57: 4584-4586.

14. Munoz-Price LS, Weinstein RA (2008) Acinetobacter infection. N Engl J Med 358: 1271-1281.

15. Zurita J, Parra H, Cartelle Gestal M, McDermott J, Pedro B (2015) First case of NDM-1 producing Providencia retggeri in Ecuador. J Global Antimicrobial Resistance 3: 302-303.

\section{Corresponding author}

Monica Cartelle Gestal, PhD

P.I. Biomedical Research Unit

Zurita \& Zurita Laboratories

Avenida de la Prensa N49-221

170511 Quito, Ecuador

Phone: 0984237996

Fax: 5932242777

Email: mcarges@gmail.com

Conflict of interests: No conflict of interests is declared. 